\title{
Refrigeration or anti-theft? Food-caching behavior of wolverines (Gulo gulo) in Scandinavia
}

\author{
Bert van der Veen ${ }^{1,2} \cdot$ Jenny Mattisson ${ }^{3}$ (D) $\cdot$ Barbara Zimmermann ${ }^{1} \cdot$ John Odden $^{4} \cdot$ Jens Persson $^{5}$
}

Received: 21 October 2019 / Revised: 23 February 2020 / Accepted: 3 March 2020 / Published online: 15 April 2020

(C) The Author(s) 2020

\begin{abstract}
Food-caching animals can gain nutritional advantages by buffering seasonality in food availability, especially during times of scarcity. The wolverine (Gulo gulo) is a facultative predator that occupies environments of low productivity. As an adaptation to fluctuating food availability, wolverines cache perishable food in snow, boulders, and bogs for short- and long-term storage. We studied caching behavior of 38 GPS-collared wolverines in four study areas in Scandinavia. By investigating clusters of GPS locations, we identified a total of 303 food caches from 17 male and 21 female wolverines. Wolverines cached food all year around, from both scavenging and predation events, and spaced their caches widely within their home range. Wolverines cached food items on average $1.1 \mathrm{~km}$ from the food source and made between 1 and 6 caches per source. Wolverines cached closer to the source when scavenging carcasses killed by other large carnivores; this might be a strategy to optimize food gain when under pressure of interspecific competition. When caching, wolverines selected for steep and rugged terrain in unproductive habitat types or in forest, indicating a preference for less-exposed sites that can provide cold storage and/or protection against pilferage. The observed year-round investment in caching by wolverines underlines the importance of food predictability for survival and reproductive success in this species. Increasing temperatures as a consequence of climate change may provide new challenges for wolverines by negatively affecting the preservation of cached food and by increasing competition from pilferers that benefit from a warmer climate. It is however still not fully understood which consequences this may have for the demography and behavior of the wolverine.
\end{abstract}

\section{Significance statement}

Food caching is a behavioral strategy used by a wide range of animals to store food for future use. Choosing appropriate caching sites appears important for slowing down decomposition rates and minimizes competition. In this study, we demonstrate that the wolverine, an opportunistic predator and scavenger, utilizes available carrion to create caches all year around. By following wolverines with GPS collars, we registered that they carried food far away to cache it in secluded and cold places, which are often located on steep slopes or in forest. However, when scavenging other carnivores' prey, they move food in shorter distances, possibly to be able to quickly return for more. The observed efficiency in wolverine caching behavior is likely vital for their survival and reproductive success in the harsh and highly seasonal environment in which they live.

Bert van der Veen and Jenny Mattisson contributed equally to this work.

Communicated by C. Soulsbury

Electronic supplementary material The online version of this article (https://doi.org/10.1007/s00265-020-2823-4) contains supplementary material, which is available to authorized users.

Jenny Mattisson

jenny.mattisson@nina.no

1 Faculty of Applied Ecology, Agricultural Sciences and Biotechnology, Inland Norway University of Applied Sciences (INN), NO-2480 Koppang, Norway

2 Norwegian Institute of Bioeconomy Research (NIBIO), NO-7031 Trondheim, Norway
3 Norwegian Institute for Nature Research (NINA), NO-7485 Trondheim, Norway

4 Norwegian Institute for Nature Research (NINA), NO-0349 Oslo, Norway

5 Grimsö Wildlife Research Station, Department of Ecology, Swedish University of Agricultural Science, SE-730 91 Riddarhyttan, Sweden 
Keywords Carnivore $\cdot$ Climate change $\cdot$ Mustelid $\cdot$ Resource selection $\cdot$ Scatter hoarding $\cdot$ Seasonality

\section{Introduction}

Food caching is a widespread behavior in mammals, birds, and arthropods (Vander Wall 1990; Sutton et al. 2016). Food-caching animals can gain a nutritional or energetic advantage through this behavior, as it can buffer seasonality in food availability and increase the spatial distribution of their food supply in times of scarcity (Vander Wall 1990). Access to cached food may be crucial, especially during periods of high energy demands, such as lactation and the rearing of young (Gittleman and Thompson 1988; Persson 2005; Inman et al. 2012a; Derbyshire et al. 2015). Food-caching behavior involves the following: (1) the storage of food before consumption, through transport, placement, and concealment; and (2) the recovery and consumption of the cache food (Vander Wall 1990).

For caching behavior to be advantageous, the gain from storage and recovery should outweigh the cost of caching (Andersson and Krebs 1978; Alpern et al. 2012). Animals have evolved several strategies to maximize the benefits of caching, such as preventing or minimizing competition through cache placement, concealment, and dispersion, by optimizing transport distance (Stapanian and Smith 1978; Rong et al. 2013), and through varying recovery strategies. Recovery can occur through olfactory or visual senses, spatial memory, or in opportunistic manner (Kamil and Balda 1985; Vander Wall 1990; Phillips et al. 1991; Vander Wall and Jenkins 2003). Food items can be either stored closely together (larder hoarding; Jenkins and Breck 1998) or as dispersed caches (scatter hoarding; Brodin 2010), and for short-term (hours to days) or long-term periods (weeks to months, Vander Wall 1990; or even years, Smith 1968). Long-term caching of seeds and nuts is a common behavior of several bird species (Clayton and Krebs 1995) and rodents (Aleksiuk 1970; Wauters et al. 1995). Short-term caching has been observed in several large northern predators such as bears (Ursus spp.; Elgmork 1982) and the Eurasian lynx (Lynx lynx; Jedrzejewski et al. 1993; Øvrum 2000), who cover their prey with snow, earth, or plant material when temporarily leaving the carcass (Vander Wall 1990).

Many mustelid species are known to cache food, e.g., the least weasel (Mustela nivalis; Criddle 1947), the Eurasian otter (Lutra lutra; Lanszki et al. 2006), the American mink (Neovision vision; Yeager 1943), the American marten (Martes americana; Henry et al. 1990), the Tayra (Eira barbara; Soley and Alvarado-Díaz 2011), and the American badger (Taxidae taxus; Michener 2000). The world's largest terrestrial mustelid, the wolverine (Gulo gulo), inhabits unproductive and highly seasonal environments in boreal forests and alpine tundra in the northern hemisphere (Inman et al. 2012a). As a facultative predator and scavenger, the wolverine benefits from an opportunistic food acquisition strategy (Lofroth et al. 2007; Van Dijk et al. 2008; Inman et al. 2012a; Mattisson et al. 2016). Morphologically and behaviorally, the wolverine is well adapted to roam large areas in search of carcasses (Banci 1994). Ungulates are an important part of the wolverine's diet in most areas, although diet composition shifts according to available resources (Van Dijk et al. 2008; Dalerum et al. 2009; Mattisson et al. 2016). While it is generally accepted that wolverines cache food for later consumption (Krott 1960; Haglund 1966; Inman et al. 2012a), few studies have described their food-caching behavior (but see Magoun 1987; Samelius et al. 2002; Wright and Ernst 2004). Caching facilitates the occupancy of unproductive habitat by improving food predictability and by allowing wolverines to take advantage of sudden food bonanzas (Vander Wall 1990; Inman et al. 2012a). Wolverine food caches are mostly located in secluded and cold microhabitats (e.g., snow, swamps, and cavities under boulders), referred to as "natural refrigerators" in the literature (Haglund 1966; Bevanger 1992; Inman et al. 2012a). Food degradation by insects and bacteria can be slowed down by caching food in cold and dark environments (Sutton et al. 2016). As wolverines cache highly perishable food (i.e., meat) for long-term storage, the wolverine is predicted to be one of the caching vertebrates most susceptible to climate change (Sutton et al. 2016). Caching structures that function as natural refrigerators can also reduce competition from other scavengers (Hopewell et al. 2008) by decreasing pilfering (Vander Wall and Jenkins 2003). The cache site can protect food from degradation and from pilferers that rely on visual or olfactory senses. Wolverine caching behavior can thus fit two, in literature proposed, hypotheses: the habitat structure hypothesis (i.e., careful cache placement in specific habitat, to decrease the probability of losing large quantities of food to pilferers; Steele et al. 2013) and the refrigeration hypothesis (i.e., storage in caches that preserve food well; Inman et al. 2012a), but these might be difficult to disentangle in practice.

The goal of this study was to describe different spatial components of the wolverine's caching behavior. We discuss our findings in the perspective of the habitat structure hypothesis and the refrigeration hypothesis. First, we aimed to assess whether wolverines are scatter hoarders or larder hoarders. Spreading caches across space can reduce the risk of pilferage (Vander Wall 1990) but requires more sophisticated spatial cognition for cache recovery. Scattered hoarding fits well within the territorial defense behavior displayed by wolverines (Mattisson et al. 2011b). Secondly, we investigated selection of caching locations by wolverines. We expected wolverines to select locations with favorable conditions for both preservation of food (i.e., cold, dark places) and protection from 
chemically and visually orientated pilferers. In winter, snow coverage provides plentiful opportunities for caching. For long-term storage (after snowmelt), we expected underlying structures (e.g., secluded cavities in-between boulders) to be important. Boulder structures are most common in steep and rugged terrain, offering many potential microhabitat structures suitable for caching year around. North- and east-facing slopes retain snow longer in spring and remain cooler in summer due to shorter sun exposure and can therefore be expected to preserve cached food longer. Selection of specific locations for caching may be more critical in summer than in winter because of the lack of snow in summer. Thirdly, we estimated the distance at which wolverines transported food items from a food source to a caching site. It has been suggested that caching should occur quickly and in close proximity to the source (Clarkson et al. 1986), as caching at long distances reduces the available time for removing food at the source, especially if other competitors are present (Hopewell et al. 2008). Long distances will also increase traveling costs but might, on the other hand, offer better caching habitat for longterm storage, as well as better food dispersion within a territory. To maximize food gain under competition pressure, we expect wolverines to transport food shorter distances when scavenging from ungulate carcasses that were killed by another carnivore than if killed by the wolverine itself. Similar, when scavenging on ungulates that died of natural causes, competition is excepted to be high as other scavengers most likely are present before, or at the same time as the wolverine. Additionally, wolverines might cache at far distances when competition is low to optimize suitability of caching site habitat or to increase resource dispersion.

\section{Materials and methods}

\section{Study area}

The study was carried out in four areas on the Scandinavian Peninsula Finnmark $\left(70^{\circ} 10^{\prime} \mathrm{N}, 24^{\circ} 70^{\prime} \mathrm{E}\right)$, Troms $\left(69^{\circ} 00^{\prime} \mathrm{N}\right.$, $\left.19^{\circ} 90^{\prime} \mathrm{E}\right)$, and Nord-Trøndelag $\left(64^{\circ} 30^{\prime} \mathrm{N}, 12^{\circ} 50^{\prime} \mathrm{E}\right)$ counties in Norway, and the Sarek region $\left(67^{\circ} 00^{\prime} \mathrm{N}, 17^{\circ} 40^{\prime} \mathrm{E}\right)$ in Sweden (Fig. 1). The climate in Nord-Trøndelag and Sarek is continental while Troms and Finnmark have a coastal alpine climate. All areas are generally covered with snow from November to May. Sarek, Troms, and Finnmark are dominated by alpine tundra, where mountain birch forest (Betula pubescens) forms the treeline. Patches of pine forest (Pinus sylvestris) can be found in Finnmark and Troms, while northern boreal forest, dominated by conifer (Pinus sylvestris, Picea abies), interspersed with bogs and mires, is common in Nord-Trøndelag and at lower elevations in Sarek. Sarek and Troms are characterized by steep alpine topography with peaks up to $\sim 2000$ m.a.s.l. The topography in Finnmark and

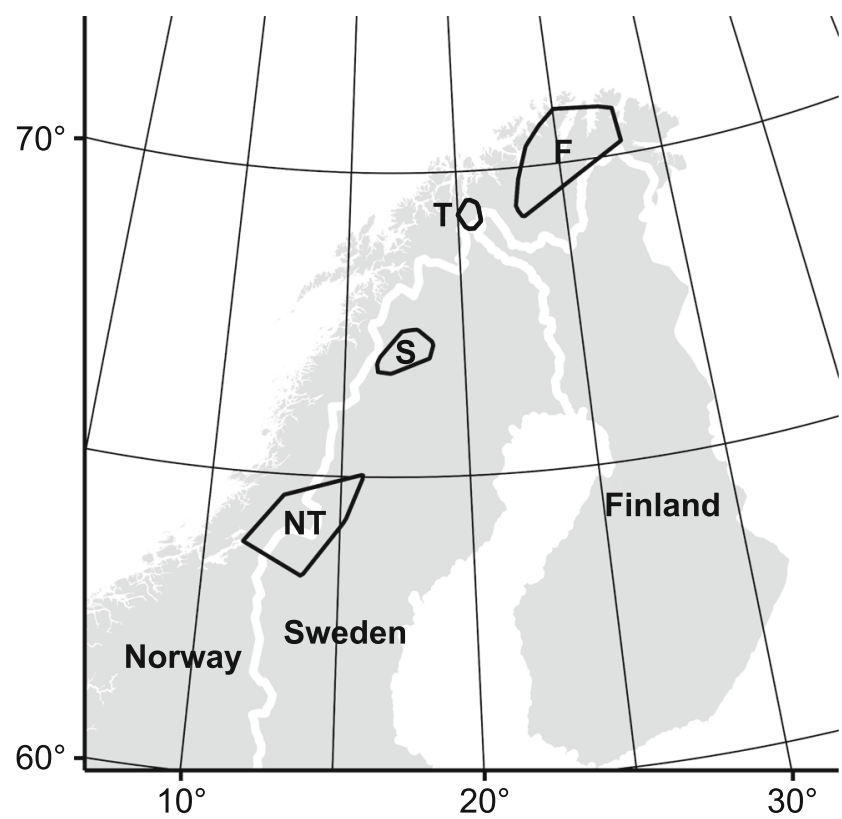

Fig. 1 The four study areas in Scandinavia. NT Nord-Trøndelag, S Sarek, $\mathrm{T}$ Troms, and F Finnmark

Nord-Trøndelag is more open and gentler than in Sarek and Troms, and with elevations ranging up to $\sim 1100$ and 1500 m.a.s.l. Free-ranging semi-domestic reindeer (Rangifer tarandus) and moose (Alces alces) are the main sources of carrion in all areas. In the Norwegian areas, free-ranging domestic sheep (Ovis aries) are also a potential source of carrion during summer in most areas. Other large carnivores present at varying densities in the study areas were Eurasian lynx and brown bears (Ursus arctos).

\section{Study animals}

Between 2008 and 2014, wolverines were anesthetized by darting from helicopter and equipped with either a GSM or UHF communication type GPS collar (GPS plus mini, Vectronic Aerospace GmbH, Berlin, Germany). Capture and handling followed existing protocols (Arnemo et al. 2012). GPS collars were originally programmed to take one to eight locations per day. Collars were reprogrammed to take between 19 and 48 locations per day in the Norwegian areas, and 38 and 96 locations per day in the Sarek area, during pre-set intensive periods of three to 8 weeks, with the aim to study diet and predation by wolverines (see Mattisson et al. 2016). Due to collar failure, some periods were shorter than planned (minimum 1 week). Age (subadult 1-2 years or adult $\geq$ 2 years), sex and reproductive status (male, single female, or female with cubs) of the wolverine, whether the wolverine had established a territory (stationary) or not (dispersing), and season (winter, October-April; summer, May-September) were assigned to each intensive monitoring period. Wolverine establishment was determined by visually studying all available 
GPS locations for each individual. If the GPS locations indicated a steady home range with no long-range movements, we considered the wolverine as stationary.

\section{Detecting food caches and food sources}

Diet studies were carried out on 38 wolverines, including 2090 monitoring days spread out over 33 intensive monitoring periods in summer and 33 periods in winter (1-4 per individual). During the intensive periods, clusters of GPS locations, defined as $\geq$ two locations within $100 \mathrm{~m}$ of each other, were identified and investigated in the field (see Mattisson et al. 2016). Initially, we visited all clusters that were possible to reach, but as our experience grew, clusters with patterns characteristic of daybeds (i.e., $\geq 2$ daytime-only consecutive locations within a very limited area, with no revisits) were given less priority. In winter, avalanche risk sometimes prohibited visits to clusters in steep terrain. Although the primary objective was to document predation events, we registered findings at all clusters. A cluster was classified as a food cache when only parts of a carcass (e.g., a leg or a head) were found, which had clearly been carried away from the site where the ungulate had died, and which had been stored by the wolverine. Holes with signs of digging, interpreted as an attempt to store or retrieve food, were also identified as food caches. We assumed that signs of caching or digging, observed at the site of the GPS locations in a cluster, were caused by the focal wolverine. A cluster was defined as a food source when we found a relatively complete carcass (from predation, natural, or unknown cause of death) or an anthropogenic food deposit such as bait stations and slaughter remains. The cause of death for ungulate carcasses was determined following the methodology in Mattisson et al. (2016) appendix S1. When we only found food remains (chewed bones and hairs) with no indication that anything had been hidden, the cluster was defined as a feeding place and thus separated from caches.

The definition of a food cache was consistent throughout the study, but the focus on caches specifically developed over time. Therefore, the registration of caches intensified in later years. It is likely that we have underestimated the number of caches by wolverines in the beginning of the study. Additionally, when a cluster was registered as a cache, we did not always register details such as microhabitat (e.g., boulder cavities, bogs, or snow) or species of the stored food item. It was also harder to document caches in winter, as we did not want to cause unnecessary disturbance by digging out holes found in the snow to document potential food items. Additionally, we may have failed to detect well-hidden caches with no signs of activity, for example, in bogs, or during winter when the wind in combination with snowfall can rapidly cover signs of food caching. Consequently, we were unable to analyze seasonal and individual differences in the number of created and utilized caches.
When possible, food caches were linked with a food source using wolverine GPS locations. Wolverines often displayed a repeated track between the food source and various cache locations (Supplementary material Fig. S1, S2). This linkage was occasionally confirmed in the field by snow tracking or by linking the species and age of cached food to the source. We often found prey items of very different age at the same caching site indicating that the caching site had been reused by the wolverine. This makes it difficult to determine whether a cache that could not be linked to a food source was newly created when discovered (i.e., the wolverine just moved a food item there) or utilized (i.e., the wolverine visited the cache to either eat, control, or restock it). If a wolverine only passed a carcass to take a single food item and did not stop or return, no cluster would have been formed ( $\geq 2$ GPS locations), and we would not have detected the food source.

It was not possible to record data blindly because our study only involved focal animals in the field.

\section{Cache dispersion}

We visualized the cache dispersion pattern per intensive period for wolverines with $\geq 10$ food caches, including six intensive periods (summer only) from five wolverines (Supplementary material Table S1). Two dispersing individuals with sufficient sample sizes were excluded, as they did not maintain a home range, and the lack of a territory is likely to influence cache dispersion.

We created separate $100 \%$ minimum convex polygons (MCPs) for the areas utilized by the wolverines during each of the intensive periods, and plotted these together with the associated caches and food sources, to illustrate the spatial spreading of the caches and whether the location of the cache was influenced by the location of the source. Additionally, to compare how the utilized area and caching pattern related to individual home ranges, we estimated and plotted home ranges $(100 \% \mathrm{MCP})$ based on all available GPS locations for each wolverine. The duration of periods used to estimate individual home ranges differed between individuals (Supplementary material Table S1). However, wolverines use $>75 \%$ of their entire multi-year home range within a month (Inman et al. 2012b); thus, home ranges calculated for short-term periods (3 months) should still give a representative reflection of their complete home range. We additionally calculated the Euclidean distance between all caches per stationary individual as an attempt to further describe the spacing of caches.

\section{Selection of habitat for caching sites}

Selection of habitat for caching sites occurs when the cache is created, i.e., when a food item is moved there. Therefore, to characterize habitats that were chosen as caching sites by 
wolverines, we only included caches that we could link to a food source (86 in summer and 42 in winter). By doing this, we could safely assume that food was cached at these sites when the cluster of GPS locations was formed (and not during a recovery attempt). To determine habitat availability near the food source, we created 20 random locations inside a buffer zone around the source, with a radius equal to the 90th percentile of the distance between sources and caches in this study (2638 m).

As the microhabitat at food caches was only registered in the field for $46 \%$ of the caches, and was not available for random locations, we used environmental maps to retrieve the habitat for all locations. These maps poorly represent the microhabitat used by wolverines for caching, but rather reflect the general habitat at the caching site. We intersected the cache and random locations with the following environmental raster maps: vegetation (Swedish Corine land cover map Lantmäteriet, $25 \times 25 \mathrm{~m}$ merged with Northern Research Institute's vegetation map, Norway, $30 \times 30 \mathrm{~m}$ into a $25 \times$ $25 \mathrm{~m}$ raster), elevation, slope, aspect, and ruggedness, all derived from DEM $50 \times 50 \mathrm{~m}$ (Norge digital Statens kartverk, Geographical data Sweden, Lantmäteriet). Ruggedness was calculated from the elevation map as vector ruggedness measure index (Sappington et al. 2007) with neighborhood size three (to include all neighboring cells) in GRASS GIS 7 (GRASS Development Team 2017). Due to the relatively small sample size of caches, we grouped the original vegetation classes into four classes: barren areas, forest, open areas with vegetation, and snow-patch vegetation (Supplementary material Table S2). However, a very low sample size in barren areas in winter forced us to pool this class with snow-patch vegetation in winter. One cache was excluded as it was located outside available environmental maps. All spatial analyses were performed in R 3.1.1 (R Development Core Team 2017) with the packages $s p$ (Pebesma and Bivand 2005) and raster (Hijmans 2016), or in QGIS 2.14-Essen (QGIS Development Team 2016).

We applied a conditional logistic regression to analyze selection of habitat for caching, because it allows each cache to be linked with its random locations (thus conditioning use on availability) by including a stratum. Additionally, we included animal ID in the models as a cluster term to account for autocorrelation issues. To detect potential seasonal differences, we performed this analysis separately for summer and winter. To account for circularity in aspect, we converted degrees to radians and included the aspect as both eastness (sine) and northness (cosine) transformation. We used a pairwise Pearson rank correlation to test for collinearity among the explanatory variables $(r>0.60)$, though none of the variables was collinear. We performed model selection with the use of Akaike's information criterion corrected for small sample sizes $\left(\mathrm{AIC}_{\mathrm{c}}\right)$ and considered models to fit the data equally well if $\triangle \mathrm{AIC}_{\mathrm{c}}$ were smaller than or equal to two (Burnham and Anderson 2002). All continuous explanatory variables were initially evaluated to determine if a non-linear second order polynomial generated a better fit, according to $\mathrm{AIC}_{\mathrm{c}}$, than a linear. Only the best fit of the two was kept for further model selection. Ruggedness was transformed by taking its natural logarithm before entering the models, to limit the influence of outliers.

\section{Caching distance}

To study the mechanisms influencing transport distance between a food source and a cache, we calculated the Euclidean distance between linked caches and food sources. Because some caches were linked to two or three sources, our sample size was greater than in the habitat selection analysis. It was possible to identify 149 linked food sources and caches, 70 by females $\left(\mathrm{n}_{\text {ind. }}=16\right.$ ) and 79 by males $\left(n_{\text {ind. }}=16\right)$. To test if the habitat quality for caching was an important motivator for wolverines to cache far away from the source, we created a $\Delta$ habitat variable where we estimated the differences in habitat quality between the cache and its source. Habitat quality was estimated by predicting the odds ratio using the top-ranked habitat selection model from above. A positive $\Delta$ habitat indicates that the wolverine moved to a better habitat for caching than the one available at the food source (and the converse for a negative $\Delta$ habitat). In addition, we tested if the distance was related to the habitat quality at the caching site directly, i.e., unrelated to the habitat at the source. Transport distance may also be influenced by potential competition at the food source. To test for this, we grouped the food sources into (1) ungulates killed by the focal wolverine $(n=56)$, (2) ungulates killed by other carnivores ( $n=27)$, or (3) ungulates dying from other causes or from anthropogenic sources $(n=46)$. Among the wolverine-killed ungulates, interpretation of GPS data suggested seven ungulates to have been communally killed by two (female, male) or three (female, male, yearling male) GPS-collared wolverines. These were treated similar as when only one GPScollared wolverine had been involved in the killing. We excluded two caches made by a GPS-collared wolverine that were linked to an ungulate killed by an uncollared wolverine. The transport distance might, in these two cases, be different as the caching wolverine was not first on site. Caching distance will be restricted by home range size (which is larger for males than for females; Mattisson et al. 2011b) and can potentially be influenced by the presence of cubs; thus, we also tested for sex and reproductive status in the models.

Caching distance was analyzed using linear models. As the response variable was right-skewed, we log transformed the variable before entering it to the model. To correct for potential autocorrelation of data from the same wolverine and/or study area, we first fitted a full linear mixed-effects model (LMER) with individual wolverine and study area (combined and separately) as random factors. However, as very little of the variance were explained by the random effects (i.e., no evidence of pseudo replication), we continued with a simpler 
model excluding random factors (LM). Model selection was performed using $\mathrm{AIC}_{\mathrm{c}}$. All continuous explanatory variables were initially included as both linear and quadratic terms, but only the term generating the model with the lowest $\mathrm{AIC}_{\mathrm{c}}$ value was kept in further model selection. As the variable $\Delta$ habitat was derived using the variable habitat quality at the caching site, these could not be combined in the same model. Similarly, reproductive status could not be combined with sex as only females fit the family category. Therefore, we first set up competing models with these variables as single predictors. We continued the model selection including the variables $\Delta$ habitat and sex as they performed better than models with habitat quality at the caching site and reproductive status, according to $\mathrm{AIC}_{\mathrm{c}}$. Vegetation type was not available for either the cache or the source for five-linked caches and food sources; thus, we excluded these from the analysis. All statistical analyses were done in R 3.1.1 with the package lme4 (Bates et al. 2015).

\section{Results}

We identified 303 food caches, 146 by males ( $\left.n_{\text {ind. }}=17\right), 117$ by single females $\left(\mathrm{n}_{\text {ind }}=16\right)$, and 40 by females with cubs $\left(\mathrm{n}_{\text {ind }}=8\right)$, of which 215 were found in summer and 88 in winter. The most common microhabitats of caching sites in summer were boulder cavities $(n=72)$, excavated holes in bogs $(n=14)$, and in persistent snow patches $(n=9)$. Some caches were covered underneath moss or vegetation $(n=7)$ or completely submerged under water $(n=1)$. In winter, the ground was mostly covered with snow, and for 20 caches, we only found holes in the snow, but for an additional 14 snow-covered caches, we detected boulder cavities as the underlying microhabitat structure. For two caches, vegetation or soil was found around the holes in the snow, indicating caching below the snow cover. One cache was submerged under "non-frozen" water. Example photos of caching sites are shown in Fig. 2 and in supplementary material Fig. S3. For $72 \%$ of all caches, it was possible to identify the species of the food item. Reindeer was by far the most cached prey (84\%; $n=177)$. Other identified species were moose $(n=25)$, sheep $(n=5)$, unknown ungulate $(n=2)$, and red fox $(n=2)$. On average, we found 0.16 caches per wolverine monitoring day, ranging from none to 0.96 caches/day among all wolverine individuals. This should be regarded as a minimum estimate of caching as we did not register all caches (see methods).

In total, we found 460 food sources during the study, of which 161 were wolverine-killed ungulates (157 reindeer and 4 sheep). Other carnivores provided an additional 140 sources, mostly reindeer $(n=129)$, where lynx was the primary predator $(n=121)$. The remaining 159 sources were either ungulates that died from natural or unknown causes (106 reindeer, 33 moose, and 1 sheep), or of anthropogenic origin (11 slaughter remains and 8 bait stations). We could link 149 of all food sources to caches (32\%). These food sources were

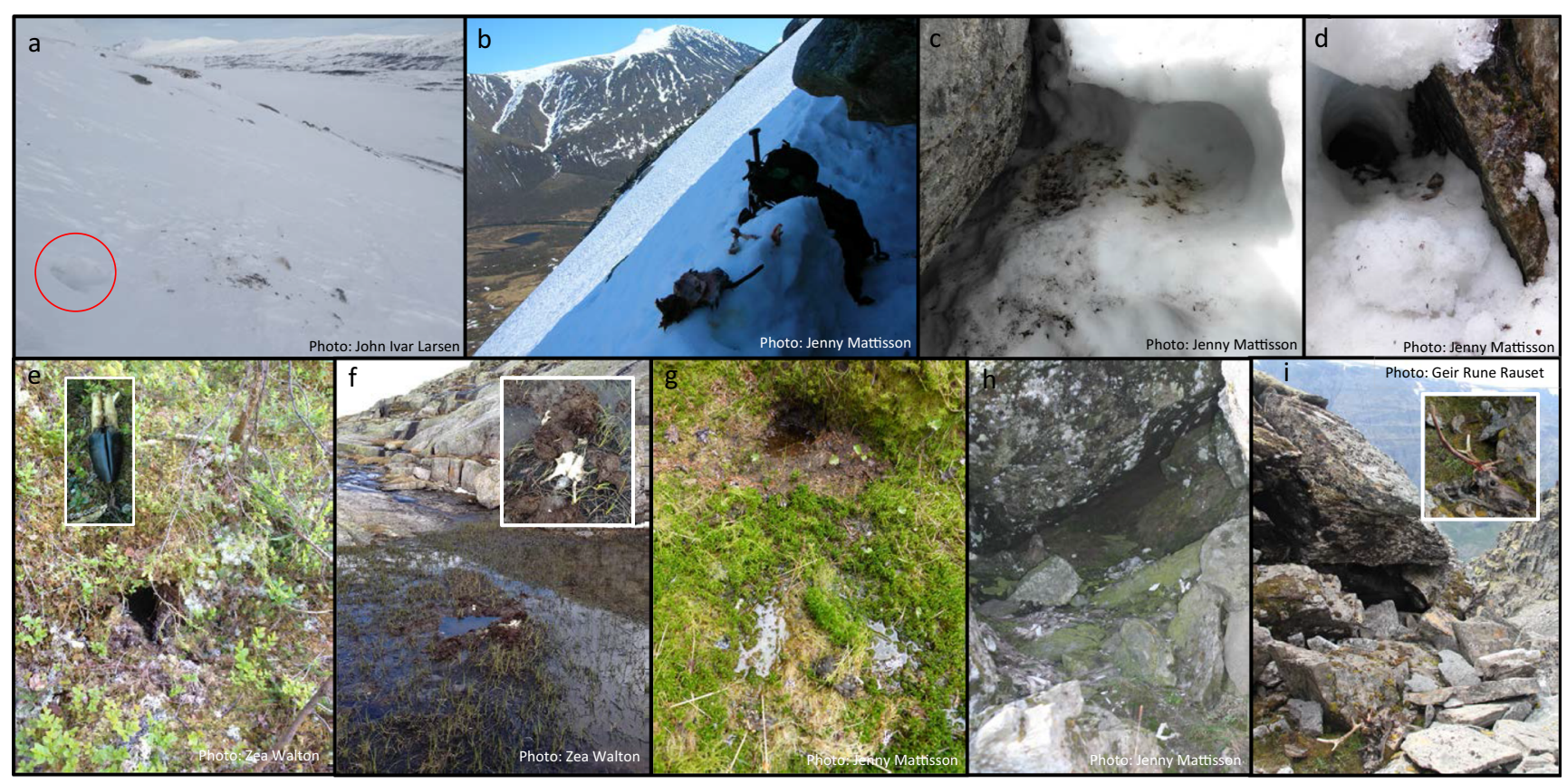

Fig. 2 Photos of caching sites in winter and late spring (a-d) and in summer $(\mathbf{e}-\mathbf{i})$. a A hole in the snow with hair of a reindeer spread around. $\mathbf{b}$ Parts of a reindeer found in a cavity between the snow and a cliff. c, $\mathbf{d}$ Remains of a reindeer becoming visible after the beginning of the snowmelt in late spring. The holes continue deep down into the remaining snow. e A hoof of a moose buried into vegetation (the hole has been exposed by us). $\mathbf{f}$ Part of a reindeer skull found in a hole in a high alpine mire. $\mathbf{g}$ A cache in a bog. $\mathbf{h}$ Well-reused caching site in boulders containing prey remains of different ages. Note the dark green moss indicating a cold and dark micro-environment. i A reindeer skull found hidden in a boulder field (now exposed) 
ungulates killed by wolverines $(n=63)$, by other carnivores ( $n=35$, including 25 known lynx-killed reindeer), or by other causes $(n=51)$.

In 14 caches, wolverines had gathered food items from more than one food source (12 caches had 2 sources and 4 had 3 sources). Furthermore, $11 \%$ of the linked food sources were the origin of more than one-documented cache (10 sources with 2 caches, 3 with 3 caches, 1 with 4 caches, and 2 with 6 caches). We documented that $21 \%$ of the food sources were visited by more than one wolverine.

\section{Cache dispersion}

Both caches and food sources were distributed across wolverine home ranges (Fig. 3), and caches were often spatially clustered around the food sources. The median distance between caches for 16 stationary females was $7.1 \mathrm{~km}(n=446$, mean $=7.2 \mathrm{~km}, \mathrm{SD}=5.98$ ) and $10.9 \mathrm{~km}$ for 8 stationary males $(n=192$, mean $=13.9 \mathrm{~km}, \mathrm{SD}=7.83)$. This approaches the approximate radius of an average home range size (females $7.9 \mathrm{~km}$, males $15.3 \mathrm{~km}$; Mattisson et al. 2011b).

\section{Selection of habitat for caching sites}

The best model for habitat selection for caching sites in both summer and winter included the polynomial term of slope and ruggedness (Table 1, Supplementary material Table S3, S4). In summer, the best model additionally included vegetation type. In both seasons, wolverines selected habitat with slopes steeper than approximately $9^{\circ}$ for caching (Fig. 4a), indicating low seasonal differentiation. Flat terrain was avoided by caching wolverines in both summer and winter, while highly rugged terrain was selected stronger in summer than in winter (Fig. 4b). In summer, wolverines selected for forest habitat and against open areas with vegetation when caching (Fig. 4c).

In summer, there were no other models within two $\mathrm{AIC}_{\mathrm{c}}$ units (Supplementary material Table S3). In winter, the separate addition of northness, eastness, or elevation to the top model increased $\mathrm{AIC}_{\mathrm{c}}$ by $1.2,1.7$, and 1.7 , respectively (Supplementary material Table S4). However, the estimates for elevation and eastness had larger standard errors than their estimates. Northness explained some variation, indicating that wolverines selected for more south-facing slopes.
Fig. 3 Plots of home ranges (dashed black lines), with food caches (o) and food sources (x) documented during periods of intensive monitoring of wolverines in summer. Area use restricted to the intensive period is shown as solid gray lines. Durations of the intensive periods and the home ranges differ between individuals (see Supplementary material Table S1). Plots $\mathbf{c}$ and $\mathbf{f}$ belong to the same male individual that expanded his home range during the study due to the death of a neighboring male wolverine. The female in plot $\mathbf{e}$ had dependent cubs. Values on $x$ and $y$ axis represent coordinates in meters, displayed in Universal Transverse Mercator (UTM) zone 33N. Note that the scale is different for different plots a

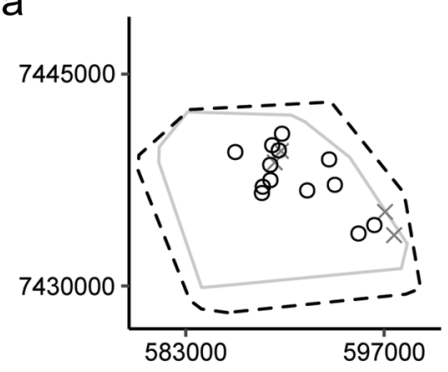

C

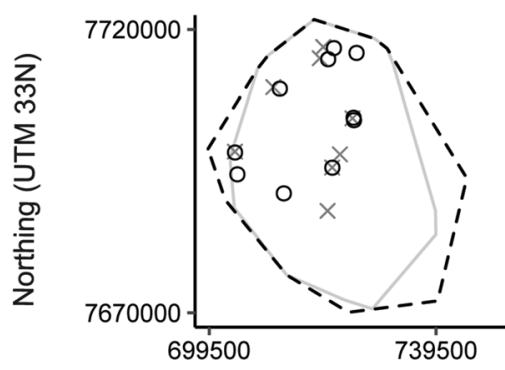

e

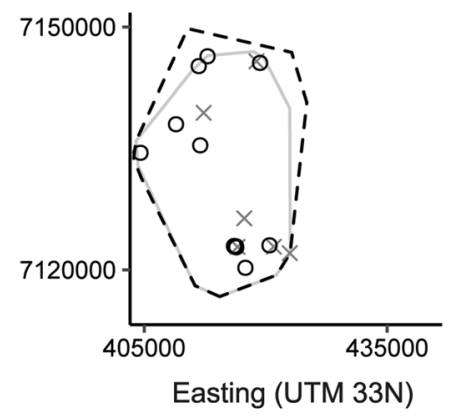

b

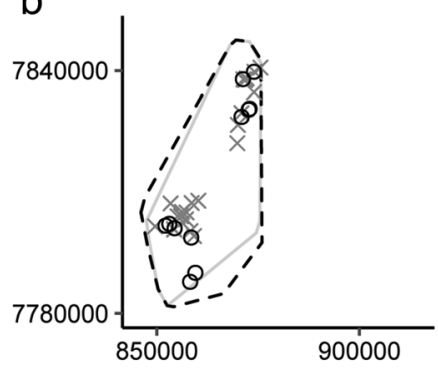

d

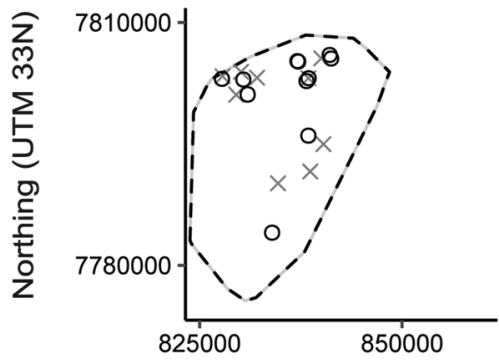

f

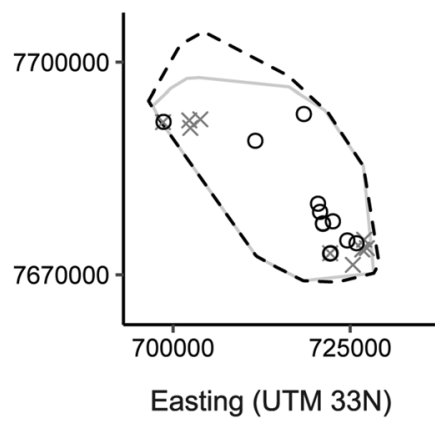


Table 1 Estimates from the best ranked conditional logistic regression models, for habitat selection at caching sites by wolverines (based on 86 foodcaching sites in summer and 42 in winter) in Scandinavia

\begin{tabular}{|c|c|c|c|c|c|c|}
\hline & \multicolumn{3}{|c|}{ Summer } & \multicolumn{3}{|l|}{ Winter } \\
\hline & $\beta^{\mathrm{a}}$ & CI $2.5 \%$ & CI $97.5 \%$ & $\beta^{\mathrm{a}}$ & CI $2.5 \%$ & CI $97.5 \%$ \\
\hline Vegetation type - forest ${ }^{b}$ & 0.38 & -0.47 & 1.22 & & & \\
\hline Vegetation type - open ${ }^{\mathrm{b}}$ & -0.74 & -1.50 & 0.03 & & & \\
\hline Vegetation type - snow-patch ${ }^{\mathrm{b}}$ & 0.11 & -0.61 & 0.83 & & & \\
\hline Slope & 34.26 & 14.86 & 53.65 & 16.63 & 3.12 & 30.15 \\
\hline Slope $^{2}$ & -8.62 & -18.05 & 7.26 & -4.04 & -12.03 & 3.95 \\
\hline $\ln$ (ruggedness) & 27.76 & 10.69 & 44.84 & 35.61 & 14.30 & 56.92 \\
\hline $\ln (\text { ruggedness })^{2}$ & -5.40 & -18.05 & 7.26 & -20.40 & -31.34 & -9.45 \\
\hline
\end{tabular}

${ }^{\mathrm{a}} \beta$ is on the logit-scale

${ }^{\mathrm{b}}$ The reference category is barren areas

\section{Caching distance}

The median distance between food sources and food caches was $499 \mathrm{~m}$ (mean $=1120 \mathrm{~m}, \mathrm{SD}=1673 \mathrm{~m}$, range $=35-$ $9329 \mathrm{~m}, n=149)$. Of all distances, $90 \%$ were shorter than $2500 \mathrm{~m}$ (Supplementary material Fig. S4). The longest distance was $9.3 \mathrm{~km}$. Based on model selection, distances between caches and sources were best explained by the origin of the food source and $\Delta$ habitat (Supplementary material Table S5). Wolverines cached food items closer to the source if the ungulate was killed by another carnivore than if it was killed by a wolverine (Fig. 5a, $\beta=0.59$, CI 95\% $=0.11-$ 1.108 ) or if the ungulate died from other causes (Fig. 5a, $\beta=0.49$, CI 95\% $=0.005-0.99$ ). Distance between the cache and the source increased when $\Delta$ habitat increased, suggesting that wolverines transported food further away from the source to find more suitable habitat (Fig. $5 \mathrm{~b}, \beta=0.16$, CI $95 \%=$ $0.06-0.25)$. In 98 cases $(68 \%)$, the habitat at the cache was superior to that at the source; in 45 cases (31\%), it was worse, and for one the same. However, the best model only explained about $12 \%$ of the observed variation $\left(R^{2}=0.12\right)$, and five other models were within two $\Delta \mathrm{AIC}_{\mathrm{c}}$ (Supplementary material Table S5). All these models included $\Delta$ habitat but with different combinations of the variable food source origin, sex, and season. Sex, included in the second, fourth, and sixth ranked models, showed slightly longer caching distances for males than for females in all models where it was included (2nd model $\beta=0.22$, CI 95\% $=-0.15-0.59$ ). Season, included in the third, fourth, fifth, and sixth ranked models, showed shorter caching distance in winter than in summer (3rd model $\beta=-0.22$, CI 95\% $=-0.62-0.18$ ).

\section{Discussion}

Wolverines visited food caches at a rate of at least one per 6 days in both winter and summer, suggesting that cached food is an important part of wolverine foraging behavior throughout the whole year. Wolverines generally inhabit unproductive and highly seasonal environments and are therefore likely to take advantage of any abundance of food resources regardless of whether it occurs in winter or in summer (Magoun 1987; Mattisson et al. 2016). Sudden food bonanzas, such as ungulates killed by avalanches, and predictable

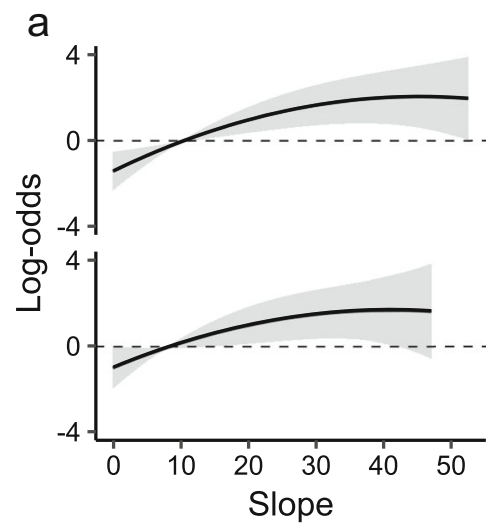

b

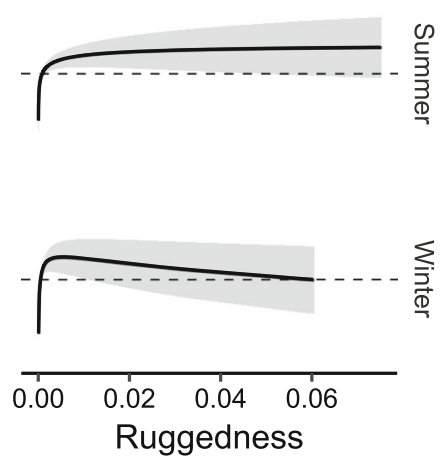

C

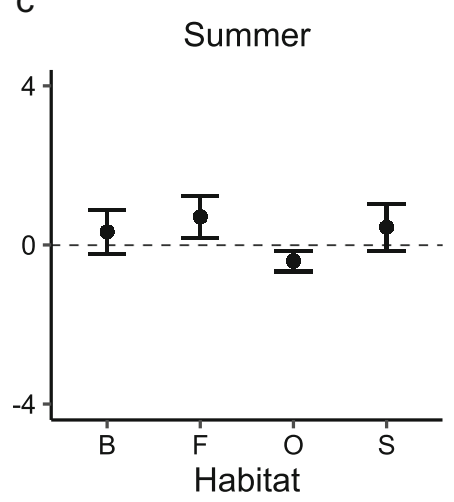

Fig. 4 Predicted log-odds with 95\% confidence intervals (shaded area and error bars) for informative variables included in the model that best explain habitat selection of wolverines for caching in Scandinavia in summer (top row) and in winter (bottom row). Slope (a), ruggedness (b), and vegetation type in summer (c; B barren areas, $\mathrm{F}$ forest, $\mathrm{O}$ open areas with vegetation, $\mathrm{S}$ snow-patch vegetation). The dashed line indicates a threshold where log-odds below the line show avoidance and above it show selection 

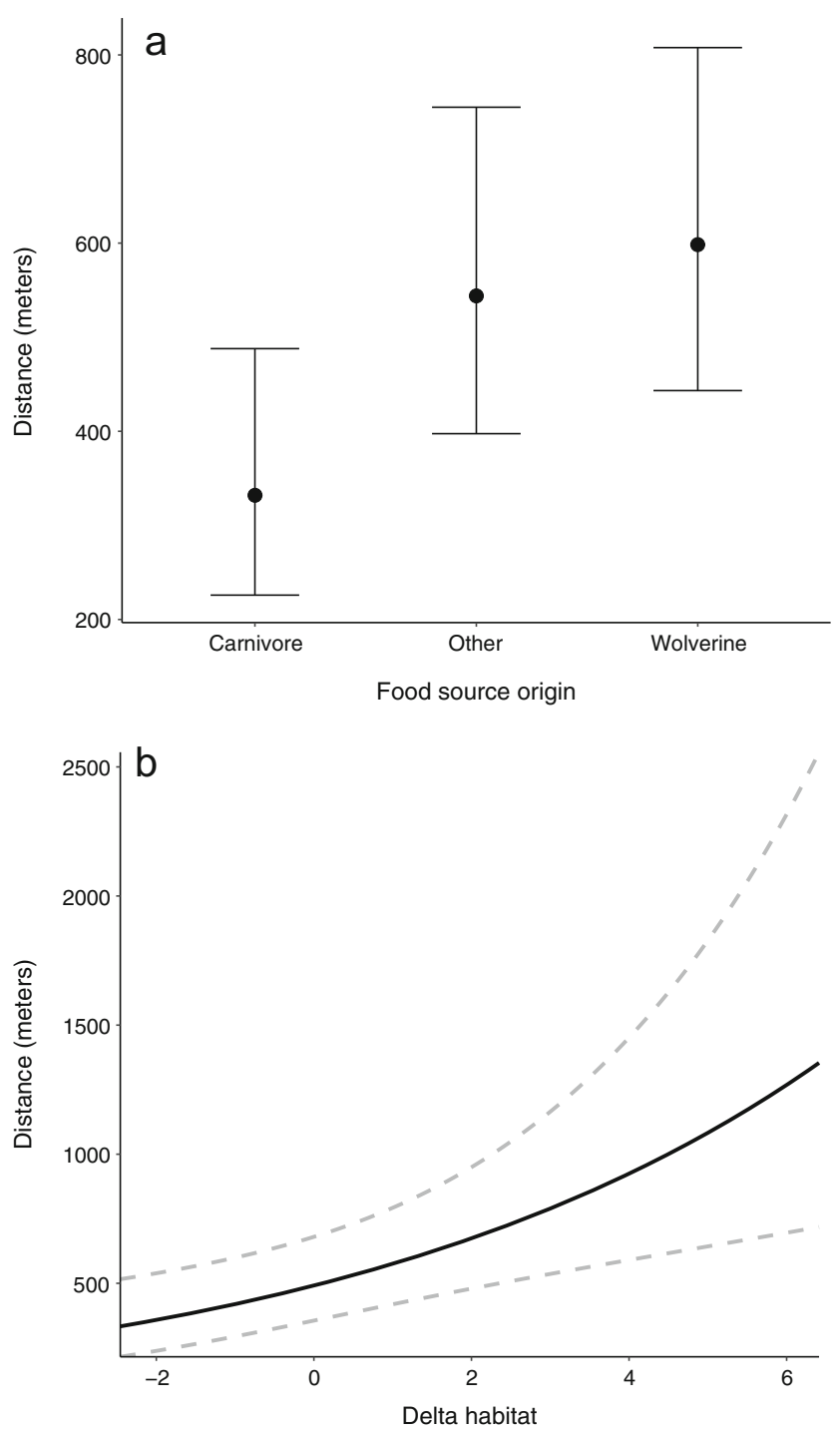

Fig. 5 Mean distance between food sources and wolverine caching sites depending on (a) the origin of the food source: ungulates killed by the wolverine $(n=60)$, ungulates killed by another carnivore species $(n=33$, of which 23 were known to be killed by lynx), or ungulates that died from other causes $(n=55)$; and (b) increasing habitat quality from the source to the cache location ( $\Delta$ habitat). Estimates are obtained from the highest ranked GLMM model and are shown with $95 \%$ confidence intervals

seasonal occurrences, such as ungulate calving periods, provide opportunities for caching that can buffer against periods of food shortage. Food shortage is expected to be most common in winter (Inman et al. 2012a), but as wolverines in northern Scandinavia largely rely on migratory semidomestic reindeer (Mattisson et al. 2016), food shortage may occur also during summer, as wolverines do not follow reindeer on their migration (Walton 2015). Most of the intensive periods included in this study were conducted during the seasons when the focal wolverine overlapped with the grazing areas of semi-domestic reindeer (Mattisson et al. 2016), but not all wolverines had access to reindeer year around (Walton 2015). The overall pattern that wolverines cache food across seasons presumably facilitates optimal exploitation of temporary availability of reindeer.

The distance between caches found in this study suggests that wolverines spread food caches across their home range. The observed cache dispersion pattern suggests that the wolverine is a scatter hoarder (Vander Wall 1990). This seems to be an efficient cache defense strategy that combines well with the overall high activity pattern (Mattisson et al. 2010; Inman et al. 2012b) and territoriality (Persson et al. 2010; Mattisson et al. 2011b) of wolverines. The defense of a territory reduces the risk of conspecifics consuming resources or robbing caches (Vander Wall 1990), thus increasing the benefits from food caching (Alpern et al. 2012). The spatial pattern we observed is likely a result of food caches being linked to where the food item becomes available and the distance the wolverine is willing to transport a food item. Scattering caches decreases the likelihood of losing large quantities of food to pilfering (Stapanian and Smith 1978; Vander Wall 2000; Leaver 2004), but increases the cost related to caching (Alpern et al. 2012) through handling, re-caching, and eventual recovery of numerous food items. As territory holders, wolverines need an extensive spatial memory of their range, aiding cache placement and recovery (Sherry 1984).

On some occasions, we observed more than one wolverine using the same caching site at the same time, or at different times. Whether these interactions at caches between overlapping territory holders (Mattisson et al. 2011b) suggest communal caching or pilferage is not known. Sharing resources may be a beneficial strategy among breeding adults with common offspring, or between parents and offspring, while unrelated individuals are mostly excluded by territorial behavior. However, young dispersing conspecifics may take the risk involved in pilfering when food is scarce.

Wolverines selected caching sites in steep and rugged terrain and preferred to cache in forest vegetation in summer, when available. However, in areas with limited forest cover, wolverines also cached in open alpine habitat with boulder structures or bogs. These habitats possibly provide a larger quantity of secluded, cold, and dark microhabitat structures that may be better suited for preserving and disguise food items when compared with flat open areas, rich in low alpine vegetation. In addition, selection of steep and rugged terrain is in accordance with general habitat selections of wolverines (Rauset et al. 2013). Contrary to our expectations, caching wolverines did not select for shaded slopes, i.e., north- or east-facing slopes. This may, however, be less important for cached food preservation when the microhabitat (i.e., snow, boulder cavities, or bogs) shields food items from the sun. Caching under forest cover and other visually occluded places might prevent avian scavengers from locating the caches. Corvid and eagle species (Aquila chrysaetos, Haliaeetus albicilla) are common in our study areas and are important competitors of wolverines at carcasses (Mattisson et al. 2011a; 
Henden et al. 2014; Gomo et al. 2017), and at least, corvids have the potential to be pilferers of wolverine caches. For example, ravens (Corvus corax) have been observed robbing caches of arctic foxes (Vulpes lagopus; Careau et al. 2007b). Caching in bogs and water can be an efficient strategy to disguise food smells from potential terrestrial pilferers, such as the red fox which is one of the most common terrestrial competitors in our study system.

Contrary to our expectations, we did not find a clear seasonal difference in habitat selection for caching sites. The lack of a seasonal selection pattern may be due to the relatively small sample size of caching sites in winter, in combination with the use of coarse-scale environmental maps that may not sufficiently describe microhabitat. In both seasons, we documented cached food items in boulder cavities, snow, water, and bogs. These structures provide cold and secluded environments that can act as natural refrigerators that delay decomposition rates of cached food by bacteria and insects (Kruuk 1972; DeVault et al. 2004; Parmenter and MacMahon 2009) and/or protect caches by masking visual and chemical clues that can attract pilferers. In winter, when microhabitat structures are covered by snow, wolverines likely rely on their spatial memory to locate suitable caching locations underneath the snow. Persistent snow cover offers ample opportunities to cache food, and selecting caching locations in snowbed habitat with late spring snow cover could prove important for food predictability during spring and earlier summer. A study that mimicked caching by cougar (Puma concolor; Bischoff-Mattson and Mattson 2009) showed that caching served to reduce competition from arthropods and microbes, in addition to lowering detection rates of other scavenging carnivores. Wolverines are known to cache in trees (Krott 1960; Haglund 1966), which does not delay decomposition of cached food, but may allow for short-term storage in areas where terrestrial scavengers form the main source of competition.

Food sources (e.g., a large ungulate carcass) used by wolverines usually contain more food than a wolverine can transport and cache in a single trip, and thus provide opportunities to cache multiple items. Caching close to the source minimizes costs associated with transport and allows wolverines to secure as much food as possible before the arrival of competitors. It is common for wolverines to scavenge from carcasses killed by other carnivores, such as lynx (Mattisson et al. 2011a), wolves (Van Dijk et al. 2008), and brown bears (Mattisson et al. 2016). However, this may involve a risk if the other carnivore defends its kill (Inman et al. 2007; Kortello et al. 2007; Jimenez et al. 2008). Wolverines reduce this risk by mainly utilizing lynx-killed carcasses after they were abandoned by the lynx (Mattisson et al. 2011a), or while the lynx was temporarily away (López-Bao et al. 2016). If we assume that wolverines are not able to know when, or if, the predator is coming back to a carcass, the shorter transport distance we observed at kills from other carnivores is a favorable strategy to quickly secure as much food as possible. However, caching in close vicinity to the carcass may increase the risk of cache pilferage (Tamura et al. 1999); also, the habitat near the carcass might not be optimal for long-term storage. When caching close to a carcass, wolverines may move caches to a more suitable site at a later time, as observed in arctic foxes whilst caching goose eggs (Careau et al. 2007a) and for other species including rodents (Waite and Reeve 1992; Rong et al. 2013) and birds (Moore et al. 2007). We found indications that wolverines cached food further away from the carcass to find more preferred habitat than the one available at the carcass. Habitat has been shown to be an important motivator to hoard further away from the source in various rodent species, likely because preferred habitat decrease cache pilferage (Wang and Corlett 2017). It is likely that other scavengers may detect carcasses prior to the wolverine, which will increase competition at the food source (Selva and Fortuna 2007; Gomo et al. 2017). High numbers of birds can consume large quantities of animal biomass over short periods of time (Selva 2004; Wikenros et al. 2013). We found that wolverines transported food items further distances when the food source was a wolverine-killed ungulate. Presumably, the wolverine was first on site and consequently had more time to find suitable caching sites and spread them further away from the carcass.

The potential influence of climate change on various aspects of wolverine ecology (e.g., denning and caching) has received increasing attention in recent years (Aubry et al. 2007; Schwartz et al. 2009; Copeland et al. 2010; McKelvey et al. 2011; Peacock 2011; Inman et al. 2012a; Webb et al. 2016; Aronsson and Persson 2017; Magoun et al. 2017). Inman et al. (2012a) proposed a "refrigeration-zone" hypothesis as a food and competition-based explanation for the observed correlation between wolverine distribution and the area encompassed by persistent spring snow cover (Copeland et al. 2010). Accordingly, the wolverine is suggested to be more susceptible to climate change than most caching vertebrates (Sutton et al. 2016). In this study, we confirm that caching is common in wolverines of both sexes all year round and that they seem to invest considerably in finding suitable caching sites. Caching in steep and rugged terrain in unproductive habitat types indicates a preference for less exposed sites that can function as natural refrigerators and minimize pilfering. The effort wolverines put into improving food predictability and increasing their food supplies underlines the importance of caching behavior for their survival and reproduction (Inman et al. 2012a). Increasing temperatures as a consequence of climate change may provide new challenges for wolverines as it affects both the preservation of cached food (Sutton et al. 2016) and may increase occurrence of potential pilferers such as the red fox (Elmhagen et al. 2015). It is however still not fully understood which consequences this may have for the demography and behavior of the wolverines. 
Acknowledgments We thank P. Segerström, E. Segerström, T. Strømseth, and J. M. Arnemo for capturing and collaring the wolverines, and the State Nature Inspectorate, reindeer herders, and all additional people that have contributed to captures and data collection in the field. A special thanks to P. Segerström and G. R. Rauset for their support and expertise, and to Z. Walton, A. Ordiz, and anonymous reviewers for fruitful comments on earlier drafts. This MS is a continuation of a master thesis by Bert van der Veen (https://brage.inn.no/inn-xmlui/bitstream/ handle/11250/2445533/vanderveen.pdf?sequence=1\&isAllowed=y).

Funding information Open Access funding provided by Norwegian institute for nature research. This work was supported by the Swedish Environmental Protection Agency, the Norwegian Environment Agency, the Research Council of Norway (Project 212919), the European Association for Zoo and Aquaria, the World Wide Fund for Nature (Sweden), the Swedish Research Council for Environment, Agricultural Sciences and Spatial Planning (Formas), the private foundations "Olle och Signhild Engkvists Stiftelser," and "Marie-Claire Cronstedts Stiftelse." The County administrations in Nord-Trøndelag, Troms, and Finnmark, the Carnivore Management Boards in regions 6 and 8, and the Reindeer Development Fund in Norway also provided considerable financial assistance.

Data availability The datasets analyzed during the current study are available at https://osf.io/8phf6(caching distance) and https://osf.io/5f46d (habitat selection).

\section{Compliance with ethical standards}

Conflict of interest The authors declare that they have no conflict of interest.

Ethical approval All applicable international, national, and/or institutional guidelines for the care and use of animals were followed. All procedures performed in studies involving animals were in accordance with the ethical standards of the institution or practice at which the studies were conducted. Capture and handling followed existing protocols (Arnemo et al. 2012) and were approved by the Swedish Animal Ethics Committee in Umeå (A11-12) and the Norwegian Experimental Animal Ethics Committee (FOTS ID2826, FOTS ID5699, FOTS ID7017).

Open Access This article is licensed under a Creative Commons Attribution 4.0 International License, which permits use, sharing, adaptation, distribution and reproduction in any medium or format, as long as you give appropriate credit to the original author(s) and the source, provide a link to the Creative Commons licence, and indicate if changes were made. The images or other third party material in this article are included in the article's Creative Commons licence, unless indicated otherwise in a credit line to the material. If material is not included in the article's Creative Commons licence and your intended use is not permitted by statutory regulation or exceeds the permitted use, you will need to obtain permission directly from the copyright holder. To view a copy of this licence, visit http://creativecommons.org/licenses/by/4.0/

\section{References}

Aleksiuk M (1970) The seasonal food regime of arctic beavers. Ecology 51:264-270. https://doi.org/10.2307/1933662

Alpern S, Fokkink R, Lidbetter T, Clayton NS (2012) A search game model of the scatter hoarder's problem. J R Soc Interface 9:869 879. https://doi.org/10.1098/rsif.2011.0581
Andersson M, Krebs J (1978) On the evolution of hoarding behaviour. Anim Behav 26:707-711. https://doi.org/10.1016/0003-3472(78) 90137-9

Arnemo JM, Evans A, Fahlman Å (2012) Biomedical protocol for freeranging brown bears, gray wolves, wolverines and lynx. http:// www1.nina.no/RovviltPub/pdf/Biomedical\%20Protocols\% 20Carnivores\%20March\%202012.pdf. Accessed 10 Mar 2020

Aronsson M, Persson J (2017) Mismatch between goals and the scale of actions constrains adaptive carnivore management: the case of the wolverine in Sweden. Anim Conserv 20:261-269. https://doi.org/ 10.1111/acv. 12310

Aubry KB, Mckelvey KS, Copeland JP (2007) Distribution and broadscale habitat relations of the wolverine in the contiguous United States. J Wildl Manag 71:2147-2158. https://doi.org/10.2193/ 2006-548

Banci V (1994) Wolverine. In: Ruggiero LF, Aubry KB, Buskirk SW, Lyon LJ, Zielinski WJ (eds) The scientific basis for conserving forest carnivores: American marten, fisher, lynx, and wolverine. USDA Forest Service General Technical Report RM-254. USDA Forest Service Rocky Mountain Forest and Range Experiment Station, Fort Collins, Colorado, USA, pp 99-127

Bates D, Mächler M, Bolker B, Walker S (2015) Fitting linear mixedeffects models using lme4. J Stat Softw 67:1-48. https://doi.org/10. 18637/jss.v067.i01

Bevanger K (1992) Report on the Norwegian wolverine (Gulo gulo L.). Small Carniv Conserv 6:8-10

Bischoff-Mattson Z, Mattson D (2009) Effects of simulated mountain lion caching on decomposition of ungulate carcasses. West $\mathrm{N}$ Am Nat 69:343-350. https://doi.org/10.3398/064.069.0308

Brodin A (2010) The history of scatter hoarding studies. Philos Trans R Soc B 365:869-881. https://doi.org/10.1098/rstb.2009.0217

Burnham KP, Anderson DR (2002) Information and likelihood theory: a basis for model selection and inference. In: Burnham KP, Anderson DR (eds) Model selection and multimodel inference: a practical information-theoretic approach. Springer-Verlag, New York, pp 49-97

Careau V, Giroux J-F, Berteaux D (2007a) Cache and carry: hoarding behavior of arctic fox. Behav Ecol Sociobiol 62:87-96. https://doi. org/10.1007/s00265-007-0441-z

Careau V, Lecomte N, Giroux J-F, Berteaux D (2007b) Common ravens raid arctic fox food caches. J Ethol 25:79-82. https://doi.org/10. 1007/s10164-006-0193-7

Clarkson K, Eden SF, Sutherland WJ, Houston AI (1986) Density dependence and magpie food hoarding. J Anim Ecol 55:111-121. https:// doi.org/10.2307/4696

Clayton NS, Krebs JR (1995) Memory in food-storing birds: from behaviour to brain. Curr Opin Neurobiol 5:149-154. https://doi.org/10. 1016/0959-4388(95)80020-4

Copeland JP, McKelvey KS, Aubry KB et al (2010) The bioclimatic envelope of the wolverine (Gulo gulo): do climatic constraints limit its geographic distribution? Can J Zool 88:233-246. https://doi.org/ 10.1139/Z09-136

Criddle S (1947) A nest of the least weasel. Can Field-Nat 61:69

Dalerum F, Kunkel K, Angerbjörn A, Shults BS (2009) Diet of wolverines (Gulo gulo) in the western Brooks Range, Alaska. Polar Res 28: 246-253. https://doi.org/10.1111/j.1751-8369.2008.00090.x

Derbyshire R, Strickland D, Norris DR (2015) Experimental evidence and 43 years of monitoring data show that food limits reproduction in a food-caching passerine. Ecology 96:3005-3015. https://doi.org/ 10.1890/15-0191.1

DeVault TL, Brisbin IL, Rhodes OE (2004) Factors influencing the acquisition of rodent carrion by vertebrate scavengers and decomposers. Can J Zool 82:502-509. https://doi.org/10.1139/z04-022

Development Core Team R (2017) R: a language and environment for statistical computing. R Foundation for Statistical Computing, Vienna, Austria. http://www.R-project.org. Accessed 10 Mar 2020 
Elgmork K (1982) Caching behavior of brown bears (Ursus arctos). J Mammal 63:607-612. https://doi.org/10.2307/1380265

Elmhagen B, Kindberg J, Hellström P, Angerbjörn A (2015) A boreal invasion in response to climate change? Range shifts and community effects in the borderland between forest and tundra. Ambio 44: $39-50$

Gittleman JL, Thompson SD (1988) Energy allocation in mammalian reproduction. Am Zool 28:863-875. https://doi.org/10.1093/icb/ 28.3.863

Gomo G, Mattisson J, Hagen BR, Moa PF, Willebrand T (2017) Scavenging on a pulsed resource: quality matters for corvids but density for mammals. BMC Ecol 17:22. https://doi.org/10.1186/ s12898-017-0132-1

GRASS Development Team (2017) Geographic resources analysis support system (GRASS GIS) software, version 7.2. Open Source Geospatial Foundation. https://grass.osgeo.org. Accessed 10 Mar 2020

Haglund B (1966) Winter habits of the lynx (Lynx lynx L.) and wolverine (Gulo gulo L.) as revealed by tracking in the snow. Viltrevy $4: 81-$ 310

Henden J-A, Stien A, Bårdsen B-J, Yoccoz NG, Ims RA (2014) Community-wide mesocarnivore response to partial ungulate migration. J Appl Ecol 51:1525-1533. https://doi.org/10.1111/1365-2664. 12328

Henry S, Raphael M, Ruggiero L (1990) Food caching and dandling by marten. Great Basin Nat 50:381-383

Hijmans RJ (2016) raster: geographic data analysis and modeling. R package. https://rdrr.io/cran/raster/. Accessed 10 Mar 2020

Hopewell LJ, Leaver LA, Lea SEG (2008) Effects of competition and food availability on travel time in scatter-hoarding gray squirrels (Sciurus carolinensis). Behav Ecol 19:1143-1149. https://doi.org/ 10.1093/beheco/arn095

Inman RM, Inman KH, Packila ML, McCue AJ (2007) Wolverine harvest in Montana: survival rates and spatial aspects of harvest management. In: Greater Yellowstone wolverine program, Cumulative Report. Wildlife Conservation Society, Ennis, pp 85-96

Inman RM, Magoun AJ, Persson J, Mattisson J (2012a) The wolverine's niche: linking reproductive chronology, caching, competition, and climate. J Mammal 93:634-644. https://doi.org/10.1644/11MAMM-A-319.1

Inman RM, Packila ML, Inman KH et al (2012b) Spatial ecology of wolverines at the southern periphery of distribution. J Wildl Manag 76:778-792. https://doi.org/10.1002/jwmg.289

Jedrzejewski W, Schmidt K, Milkowski L, Jedrzejewska B, Okarma H (1993) Foraging by lynx and its role in ungulate mortality: the local (Bialowieza Forest) and the Palaearctic viewpoints. Acta Theriol 38: 385-403

Jenkins SH, Breck SW (1998) Differences in food hoarding among six species of heteromyid rodents. J Mammal 79:1221-1233. https:// doi.org/10.2307/1383013

Jimenez MD, Asher VJ, Bergman C, Bangs EE, Woodruff SP (2008) Gray wolves, Canis lupus, killed by cougars, Puma concolor, and a grizzly bear, Ursus arctos, in Montana, Alberta, and Wyoming. Can Field-Nat 122:76-78. https://doi.org/10.22621/cfn.v122i1.550

Kamil AC, Balda RP (1985) Cache recovery and spatial memory in Clark's nutcrackers (Nucifraga columbiana). J Exp Psychol Anim Beh 11:95-111. https://doi.org/10.1037/0097-7403.11.1.95

Kortello AD, Hurd TE, Murray DL (2007) Interactions between cougars (Puma concolor) and gray wolves (Canis lupus) in Banff National Park, Alberta. Ecoscience 14:214-222. https://doi.org/10.2980/ 1195-6860(2007)14[214:IBCPCA]2.0.CO;2

Krott P (1960) Ways of the wolverine. Nat Hist 69:16-29

Kruuk H (1972) The spotted hyena: a study of predation and social behavior. University of Chicago Press, Chicago

Lanszki J, Molnár M, Molnár T (2006) Factors affecting the predation of otter (Lutra lutra) on European pond turtle (Emys orbicularis). J
Zool 270:219-226. https://doi.org/10.1111/j.1469-7998.2006. 00132.x

Leaver LA (2004) Effects of food value, predation risk, and pilferage on the caching decisions of Dipodomys merriami. Behav Ecol 15:729 734. https://doi.org/10.1093/beheco/arh070

Lofroth EC, Krebs JA, Harrower WL, Lewis D (2007) Food habits of wolverine Gulo gulo in montane ecosystems of British Columbia, Canada. Wildl Biol 13:31-37. https://doi.org/10.2981/09096396(2007)13[31:FHOWGG]2.0.CO;2

López-Bao JV, Mattisson J, Persson J, Aronsson M, Andrén H (2016) Tracking neighbours promotes the coexistence of large carnivores. Sci Rep 6:23198. https://doi.org/10.1038/srep23198

Magoun A (1987) Summer and winter diets of wolverines, Gulo gulo, in Arctic Alaska. Can Field-Nat 101:392-397

Magoun AJ, Robards MD, Packila ML, Glass TW (2017) Detecting snow at the den-site scale in wolverine denning habitat. Wildlife Soc B 41: 381-387. https://doi.org/10.1002/wsb.765

Mattisson J, Andrén H, Persson J, Segerström P (2010) Effects of species behavior on global positioning system collar fix rates. J Wildl Manag 74:557-563. https://doi.org/10.2193/2009-157

Mattisson J, Andrén H, Persson J, Segerström P (2011a) Influence of intraguild interactions on resource use by wolverines and Eurasian lynx. J Mammal 92:1321-1330. https://doi.org/10.1644/11MAMM-A-099.1

Mattisson J, Persson J, Andrén H, Segerström P (2011b) Temporal and spatial interactions between an obligate predator, the Eurasian lynx (Lynx lynx), and a facultative scavenger, the wolverine (Gulo gulo). Can J Zool 89:79-89. https://doi.org/10.1139/Z10-097

Mattisson J, Rauset GR, Odden J, Andrén H, Linnell JDC, Persson J (2016) Predation or scavenging? Prey body condition influences decision-making in a facultative predator, the wolverine. Ecosphere 7:e01407. https://doi.org/10.1002/ecs2.1407

McKelvey KS, Copeland JP, Schwartz MK, Littell JS, Aubry KB, Squires JR, Parks SA, Elsner MM, Mauger GS (2011) Climate change predicted to shift wolverine distributions, connectivity, and dispersal corridors. Ecol Appl 21:2882-2897. https://doi.org/10.1890/102206.1

Michener GR (2000) Caching of Richard's ground squirrels by North American badgers. J Mammal 81:1106-1117. https://doi.org/10. 1644/1545-1542(2000)081<1106:CORSGS>2.0.CO;2

Moore JE, McEuen AB, Swihart RK, Contreras TA, Steele MA (2007) Determinants of seed removal distance by scatter-doarding rodents in deciduous forests. Ecology 88:2529-2540. https://doi.org/10. $1890 / 07-0247.1$

Øvrum L (2000) At the scene of the crime; lynx handling of prey in Hedmark. Master thesis, Norwegian University for Science and Technology

Parmenter RR, MacMahon JA (2009) Carrion decomposition and nutrient cycling in a semiarid shrub-steppe ecosystem. Ecol Monogr 79:637-661. https://doi.org/10.1890/08-0972.1

Peacock S (2011) Projected 21st century climate change for wolverine habitats within the contiguous United States. Environ Res Lett 6: 014007. https://doi.org/10.1088/1748-9326/6/1/014007

Pebesma EJ, Bivand RS (2005) Classes and methods for spatial data in R. R News 5:9-13

Persson J (2005) Female wolverine (Gulo gulo) reproduction: reproductive costs and winter food availability. Can J Zool 83:1453-1459. https://doi.org/10.1139/z05-143

Persson J, Wedholm P, Segerström P (2010) Space use and territoriality of wolverines (Gulo gulo) in northern Scandinavia. Eur J Wildl Res 56: 49-57. https://doi.org/10.1007/s10344-009-0290-3

Phillips DP, Ryon J, Danilchuk W, Fentress JC (1991) Food caching in captive coyotes: stereotypy of action sequence and spatial distribution of cache sites. Can J Psychol 45:83-91 
QGIS Development Team (2016) QGIS geographic information system. Open Source Geospatial Foundation. https://www.qgis.org/en/site/. Accessed 10 Mar 2020

Rauset GR, Mattisson J, Andrén H, Chapron G, Persson J (2013) When species ranges meet: assessing differences in habitat selection between sympatric large carnivores. Oecologia 172:701-711. https:// doi.org/10.1007/s00442-012-2546-y

Rong K, Yang H, Ma J, Zong C, Cai T (2013) Food availability and animal space use both determine cache density of Eurasian red squirrels. PLoS One 8:e80632. https://doi.org/10.1371/journal.pone. 0080632

Samelius G, Alisauskas RT, Larivière S, Bergman C, Hendrickson CJ, Phipps K, Wood C (2002) Foraging behaviours of wolverines at a large arctic goose colony. Arctic 55:148-150. https://doi.org/10. 14430/arctic699

Sappington JM, Longshore KM, Thompson DB (2007) Quantifying landscape ruggedness for animal habitat analysis: a case study using bighorn sheep in the Mojave Desert. J Wildl Manag 71:1419-1426. https://doi.org/10.2193/2005-723

Schwartz MK, Copeland JP, Anderson NJ, Squires JR, Inman RM, McKelvey KS, Pilgrim KL, Waits LP, Cushman SA (2009) Wolverine gene flow across a narrow climatic niche. Ecology 90: 3222-3232. https://doi.org/10.1890/08-1287.1

Selva N (2004) The role of scavenging in the predator community of bialowieza primeval forest. Doctoral thesis, Polish Academy of Sciences

Selva N, Fortuna MA (2007) The nested structure of a scavenger community. Proc R Soc Lond B 274:1101-1108. https://doi.org/10. 1098/rspb.2006.0232

Sherry D (1984) Food storage by black capped chikadees: memory for the location and contents of caches. Anim Behav 32:451-464. https:// doi.org/10.1016/S0003-3472(84)80281-X

Smith MC (1968) Red squirrel responses to spruce cone failure in interior Alaska. J Wildl Manag 32:305-317. https://doi.org/10.2307/ 3798975

Soley FG, Alvarado-Díaz I (2011) Prospective thinking in a mustelid? Eira barbara (Carnivora) cache unripe fruits to consume them once ripened. Naturwissenschaften 98:693-698. https://doi.org/10.1007/ s00114-011-0821-0

Stapanian MA, Smith CC (1978) A model for seed scatterhoarding: coevolution of fox squirrels and black walnuts. Ecology 59:884-896. https://doi.org/10.2307/193854

Steele MA, Contreras TA, Hadj-Chikh LZ, Agosta SJ, Smallwood PD, Tomlinson CN (2013) Do scatter hoarders trade off increased predation risks for lower rates of cache pilferage? Behav Ecol 25:206215. https://doi.org/10.1093/beheco/art107

Sutton AO, Strickland D, Norris DR (2016) Food storage in a changing world: implications of climate change for food-caching species.
Clim Change Responses 3:12-25. https://doi.org/10.1186/s40665016-0025-0

Tamura N, Hashimoto Y, Hayashi F (1999) Optimal distances for squirrels to transport and hoard walnuts. Anim Behav 58:635-642. https://doi.org/10.1006/anbe.1999.1163

Van Dijk J, Gustavsen L, Mysterud A, May R, Flagstad Ø, Brøseth H, Andersen R, Andersen R, Steen H, Landa A (2008) Diet shift of a facultative scavenger, the wolverine, following recolonization of wolves. J Anim Ecol 77:1183-1190. https://doi.org/10.1111/j. 1365-2656.2008.01445.x

Vander Wall SB (1990) Food hoarding in animals. University of Chicago Press, Chicago

Vander Wall SB (2000) The influence of environmental conditions on cache recovery and cache pilferage by yellow pine chipmunks (Tamias amoenus) and deer mice (Peromyscus maniculatus). Behav Ecol 11:544-549. https://doi.org/10.1093/beheco/11.5.544

Vander Wall SB, Jenkins SH (2003) Reciprocal pilferage and the evolution of food-hoarding behavior. Behav Ecol 14:656-667. https://doi. org/10.1093/beheco/arg064

Waite TA, Reeve JD (1992) Caching behaviour in the gray jay and the source-departure decision for rate-maximizing scatterhoarders. Behaviour 120:51-68. https://doi.org/10.1163/156853992X00200

Walton Z (2015) Eurasian lynx (Lynx lynx) and wolverine (Gulo gulo) response to seasonal variation in prey availability: influences on space use, seasonal site fidelity and reproduction. Master thesis, Høgskolen i Hedmark

Wang B, Corlett RT (2017) Scatter-hoarding rodents select different caching habitats for seeds with different traits. Ecosphere 8:e01774. https://doi.org/10.1002/ecs2.1774

Wauters LA, Suhonen J, Dhondt AA (1995) Fitness consequences of hoarding behaviour in the Eurasian red squirrel. Proc R Soc Lond B 262:277-281. https://doi.org/10.1098/rspb.1995.0206

Webb SM, Anderson RB, Manzer DL, Abercrombie B, Bildson B, Scrafford MA, Boyce MS (2016) Distribution of female wolverines relative to snow cover, Alberta, Canada. J Wildl Manag 80:14611470. https://doi.org/10.1002/jwmg.21137

Wikenros C, Sand H, Ahlqvist P, Liberg O (2013) Biomass flow and scavengers use of carcasses after re-colonization of an apex predator. PLoS One 8:e77373. https://doi.org/10.1371/journal.pone.0077373

Wright JD, Ernst J (2004) Wolverine, Gulo gulo luscus, resting sites and caching behavior in the boreal forest. Can Field-Nat 118:61-64. https://doi.org/10.22621/cfn.v118i1.883

Yeager LE (1943) Storing of muskrats and other foods by minks. J Mammal 24:100-101

Publisher's note Springer Nature remains neutral with regard to jurisdictional claims in published maps and institutional affiliations. 